\title{
Information for the patient: Travelling with HIV
}

\author{
M OSTROWSKI MD FRCPC, D TESSIER MD CCFP FCFP, JS KEYSTONE MD FRCPC
}

$\mathrm{T}$ RAVEL CAN BE ONE OF THE MOST REWARDING AND PLEASURable experiences. It can boost your morale and provide important new perspectives. However, travel to some foreign countries is associated with an increased risk of infections because of exposure to different and often exotic pathogens, especially in topical climates. Although most travellers can easily clear these pathogens with appropriate treatment, the presence of human immunodeficiency virus (HIV) infection imposes added risks.

Before finalizing travel plans, the HIV-infected person needs to obtain information on a variety of subjects: restrictions at border crossings; infectious risks, including malaria, tuberculosis and travellers' diarrhea; immunizations required and recommended; health care resources abroad, especially for those at risk for complications of HIV infection; possible interaction between medications for HIV-related conditions and prophylaxis or treatment of infectious diseases; sun photosensitivity induced by medications; and health insurance coverage. Thus, travellers with HIV infection must be especially diligent in discussing their travel plans and itinerary with their physicians.

Remember that you are the only one who can decide what risks are acceptable for you. The role of your physician is not to tell you where to go or not to go. His or her role is to explain the risks clearly to help you make your plans.

This review addresses problems of the adult traveller only.

\section{SUSCEPTIBILITY TO INFECTIONS}

The types of infections encountered by travellers vary with the geographical location, season of the year and the activities pursued. For example, you are more likely to develop a gastrointestinal infection while travelling in a developing country and staying with local residents than while vacationing at a five-star resort hotel in Scandinavia. The risks of travel to western Europe, Australia, Japan and the United States are similar to those you might encounter in Canada.

If you are planning to travel to tropical areas you should arrange to have your pretravel assessment at least six weeks before departure, because you will likely require a number of vaccinations (or inoculations). Your physician should carefully review your itinerary and assess your immune status (CD4 cell count) in order to identify your risks for infectious diseases. Infections to which a traveller might be exposed are discussed in the following categories: gastrointestinal infections, respiratory tract infections, vector-borne disease, sexually transmitted diseases (STDS) and others, including opportunistic infections. Vaccine-preventable infections are reviewed at the end of this section.

Gastrointestinal infections: Gastrointestinal infections causing nausea, vomiting or diarrhea occur in up to $40 \%$ of visitors to developing countries where fecal contamination of food and water is usual. Many patients with HIV infection are more susceptible to these infections because of low stomach acid. If you have chronic diarrhea before travel, the superimposition of another infection may cause serious illness requiring hospitalization. Instead of being a self-limited illness, as is usually the case in persons with a normal immune system, travellers' diarrhea may be prolonged or the bacteria may leave the gut and enter the bloodstream in HIV-infected persons. Examples of gastrointestinal infections that occur with a greater frequency and/or severity in HIV-infected individuals include hepatitis A, toxin-producing Escherichia coli, campylobacter, salmonella, shigella, cryptosporidia, isospora and cyclospora.

Tropical Disease Unit, The Toronto Hospital, Division of Infectious Disease, Department of Medicine, University of Toronto, Toronto, Ontario, and Centre de Médecine des Voyages du Québec, Hôpital Saint-Luc, Montréal, Québec

Correspondence: Dr JS Keystone, Tropical Disease Unit, The Toronto Hospital, 200 Elizabeth Street, eng-214, Toronto, Ontario M5G 2 C4. Telephone 416-340-3671, fax 416-595-5826

Received for publication April 12, 1995. Accepted October 4, 1995 
TABLE 1

Vector-borne diseases

\begin{tabular}{|c|c|c|c|c|}
\hline Vector & Biting time & Disease & Location & Geography \\
\hline Mosquito & Dusk to dawn & Yellow fever & Rural & Africa, South America, Panama \\
\hline Mosquito & Dusk to dawn & Malaria & $\begin{array}{l}\text { Rural only } \\
\text { Rural and urban }\end{array}$ & $\begin{array}{l}\text { South and Central America, Southeast Asia } \\
\text { Africa, Asia, Oceania }\end{array}$ \\
\hline Mosquito & Day & Dengue fever & Rural and urban & Tropics, Worldwide \\
\hline Sandfly & Dusk to dawn & Leishmaniasis & Rural & $\begin{array}{l}\text { Asia, Africa, Central and South America, southern } \\
\text { Europe, Middle East }\end{array}$ \\
\hline Assassin bug & Dusk to dawn & Chagas' disease & Rural & Mexico, Central and South America \\
\hline
\end{tabular}

In developing countries, you should avoid the following to reduce exposure to these organisms: food and beverages that are at high risk of being contaminated, such as raw or undercooked shellfish, fish, meat or eggs, raw, unpeeled fruits and vegetables; tap water and ice; and unpasteurized mild and milk products. Don't eat food from street vendors. Eat only well cooked foods but drink liberally very hot or commercially bottled beverages. You should boil water to ensure destruction of cryptosporidium, a microscopic parasite that is not killed by iodine-containing purifiers that are effective against bacteria and viruses.

Daily antibiotic prophylaxis has been shown to be effective in preventing many of the bacterial causes of travel-related diarrhea. Because of the increased risk of acquiring these infections, and the potentially severe consequences of the ensuing illness, antibiotic prophylaxis should be considered for HIV-infected travellers with CD4 counts less than 250 who plan to travel in high risk areas for less than one month. If you are taking a daily dose of cotrimoxazole (Septra, Glaxo Wellcome Inc; Bactrim, Hoffmann-La Roche Ltd), there is no need to add another antibiotic. Keep in mind that bacterial resistance to cotrimoxazole is a frequent problem in many developing countries. If you are not on antibiotic prophylaxis, the most effective regimen is a once-daily dose of ciprofloxacin $(500 \mathrm{mg})$, norfloxacin (400 mg) or ofloxacin (300 mg). You should start antibiotic prophylaxis one day before travel and continue it for two days after departure from a risk area. Since individuals with HIV infection are also at higher risk for adverse drug reactions, you should weigh the risks and benefits of antibiotic prophylaxis with your physician. Those travelling off the usual tourist routes are at greatest risk. If you decide not to take antibiotic prophylaxis, your physician should give you a prescription (filled before departure) for a three- to five-day course (one tablet twice daily) of these same antibiotics to be used for self-treatment of travellers' diarrhea. Loperamide (Imodium, Janssen Pharmaceutica Inc) is also very helpful in relieving diarrheal symptoms but should be avoided if you develop severe diarrhea associated with high fever or blood in your stools. Loperamide alone is often sufficient for the treatment of mild diarrhea. However, the combination of loperamide and an antibiotic appears to be more effective than either drug used alone.

If you develop diarrhea, drink eight to 10 glasses of liquid per day. Try to include in your diet orange juice, bananas and potatoes to replace potassium losses and broth or soups to replace sodium. Also, add extra salt to your food. Avoid spices, fried foods, milk products, caffeine and chocolate. Some authors suggest that your food intake should mirror the consistency of your stools; liquid diet for watery stools, soft food for semisolid stools and solid food for normal stools.

Respiratory tract infections: Upper respiratory tract infections (eg, 'flu) are not uncommon in travellers, probably because of exposure in crowded conditions (eg, overcrowded public vehicles, markets and economy class aircraft cabins). Since chronic sinus infections are frequent in HIV-infected persons, changes in aircraft cabin pressure may exacerbate an underlying infection. Liberal use of nasal sprays or oral decongestants (pills) are recommended before landing if you are suffering from sinus problems. Influenza outbreaks occur annually in the southern hemisphere from April to September. Therefore, influenza and pneumococcal vaccines should be updated. Haemophilus influenzae type $b$ (Hib) vaccine is now recommended for all HIV-infected individuals regardless of their travel plans. Although tuberculosis (TB) is rare in travellers, the risk of infection increases with prolonged stay abroad. Since TB and HIV are double-trouble, a TB skin test should be administered before travel (as a baseline) and after a prolonged stay in an area where TB exposure is likely. Measles in AIDS patients may be particularly severe; it is crucial that HIV-infected children and adults born after 1957 be appropriately vaccinated against this virus.

Vector-borne diseases: Vector-borne diseases are infections that are transmitted by the bite of an insect (Table 1). Except for leishmaniasis and Chagas' disease, the insect-transmitted diseases listed in Table 1 are not more severe in HIV-infected individuals. Exposure to insects can be minimized by using insect repellents containing DEET on exposed parts of the body, wearing long sleeves and trousers and sleeping under permethrin-impregnated bed nets. Medication to protect against malaria should be taken as a preventative measure by all travellers to malarious areas; this issue should be discussed with your physician or a travel medicine expert. It is important to mention to the physician prescribing the antimalarials all the medications you are on. Many medications are broken down in the liver and can compete with one another for access to the systems responsible for drug inactivation. This may cause a dangerous accumulation of a drug in your blood and tissues.

STDs: Of sun, sex, sea and sand, only sex is available everywhere, every day; thus, STDS are among the most commonly reported infections in travellers, in particular gonorrhea and 
syphilis. HIV-infected persons have the potential to develop an aggressive form of syphilis that may involve the brain and become resistant to conventional treatment. You should always use a condom during sexual contact with a new partner to avoid exposure to other STDS and to avoid spreading HIV. Since chronic carriage of hepatitis B is more frequent in HIV-infected individuals, your hepatitis B immune status should be assessed and vaccination should be seriously considered if you are not already immune.

Other infections including opportunistic infections: HIV-infected individuals are at increased risk of opportunistic infections, especially when their CD4 count drops below 250. In tropical areas, these infections may occur more frequently and may be different from those encountered in Canada. Thus, the usual medications for prevention of opportunistic infections should be taken during travel. Mycoses are much more frequent in hot and humid areas. Although drops for oral infection and cream or ovules for vaginal and skin infections can be used, it is usually more convenient and effective to use a systemic antifungal such as fluconazole (Diflucan, Pfizer Canada Inc), itraconazole (Sporanox, Janssen Pharmaceutica Inc) or ketoconazole (Nizoral, Janssen Pharmaceutica Inc). Daily cotrimoxazole is an effective prevention for Pneumocystis carinii pneumonia, toxoplasmosis and infectious diarrhea. However, the increase in drug-resistant intestinal bacteria in developing countries makes cotrimoxazole a much less effective agent for the prevention of travellers' diarrhea. While taking cotrimoxazole, remember to drink liberally to avoid dehydration and to use a sunscreen with a sun protection factor (SPF) of 15 or more to protect against possible sun sensitivity. If you plan to travel for more than a month, especially if you plan a stay with locals, ask your doctor about performing a tuberculin test before departure and after your return. This test is useful even if your immune system is suppressed. If you are being treated or receiving prophylaxis for tuberculosis, don't stop your drug(s) during travel.

\section{IMMUNIZATIONS}

Immunizations or vaccines are often prepared from killed microorganisms or are 'live' when they contain an attenuated virus or bacteria not strong enough to harm a healthy individual. In the presence of a weakened immune system, these viruses or bacteria could theoretically cause a serious infection. Thus, it is generally recommended that a live vaccine not be given to such individuals, especially someone whose CD4 count is below 250. Most of these vaccines can be replaced by 'killed' vaccines or those produced by genetic engineering with no added risk. When a live vaccine is required for which no alternative is available, eg, yellow fever vaccine, the risk of acquiring the infection must be weighed against the risk of the immunization, each case being evaluated individually.

Immunizations for the traveller are often divided into two groups: those required for entry into a country, usually for public health considerations, and those recommended for the protection of the traveller.

Required immunizations: Required immunizations are those that are necessary in order to be allowed to cross an in- ternational border. There are only three vaccines (for yellow fever, cholera and meningococcal meningitis) in this list. Evidence for yellow fever vaccination is required from travellers planning to enter most tropical countries of Africa and South America or sometimes from travellers coming from infected or endemic areas. Your exact travel itinerary should be reviewed to ascertain whether there is a need for this live vaccine. When the area to be visited is considered to be a low risk for infection and your CD4 count is 250 or less, a waiver should be supplied by your physician. The appropriate section of the immunization certificate (yellow book) should indicate that a 'medical contraindication' exists and the usual official 'stamp' should be provided. To avoid problems with health officials overseas, it may be helpful to know that severe allergy to eggs is an acceptable medical contraindication to this vaccine.

Yellow fever is found in parts of sub-Saharan Africa, Panama and South America, but has never been seen in Asia. Since yellow fever occurs only in focal geographic areas (mostly rural) in endemic countries, it is safe to enter these countries provided that you are not visiting an area where transmission occurs. If you are planning to travel to an area in which yellow fever is found, obtain advice from your public health department or a travel clinic concerning the risk of yellow fever at your destination. If you are planning to travel to a high risk yellow fever zone, then you may be offered the vaccine. Although there is a theoretical risk of vaccine-associated illness in immunocompromised patients, HIV-positive individuals who have taken the vaccine have suffered no adverse effects.

According to the World Health Organization, cholera vaccine is no longer required for entry into any country. However, this information has not yet reached immigration health officials in some countries of Africa who insist on seeing proof of immunization. Travellers who do not wish to receive a cholera shot at a border crossing should be prepared to 'negotiate' (bakshish) with local immigration officers. Since the risk of cholera for travellers is extremely low (fewer than one case/ 500,000 travellers) and the vaccine currently available in Canada is not very effective, you should obtain a vaccination waiver "for medical reasons" from your health care provider or travel clinic.

Meningococcal vaccine is safe and effective. It is only required from pilgrims visiting Saudi Arabia during the 'Hajj'. To protect against meningococcal meningitis this vaccine is also recommended for those spending time in Kenya or Tanzania or in rural areas of sub-Saharan Africa, especially during the dry season.

Recommended immunizations: Travel is usually a good opportunity for you to update your routine (childhood and adult) immunizations if they have not been given lately. These include diphtheria, tetanus and polio (every 10 years) influenza (annually), measles, pneumococcus and $\mathrm{Hib}$ (once). Hepatitis $B$ vaccine is also safe; you should receive it before long term travel or if you plan to have new sexual partners during your trip. Ask your doctor about the possibility of a double dose schedule if you are immunocompromised. Several other vaccines are recommended for certain geographic areas and 
TABLE 2

HIV test requirements of selected countries

\begin{tabular}{|c|c|}
\hline Country & Requirement for HIV testing \\
\hline Iraq & Visitors staying more than 5 days* \\
\hline Bulgaria & Visitors staying more than 1 month \\
\hline Costa Rica & Visitors staying more than 2 months* \\
\hline Cyprus & $\begin{array}{l}\text { Foreigners working as entertainers (especially artists, dancers } \\
\text { and singers) and students from Africa }\end{array}$ \\
\hline $\begin{array}{l}\text { Algeria, Antigua and Barbuda, Austria, Belize, British Virgin Islands, China*, } \\
\text { Czech Republic, Egypt, Germany, Greece, India, Libya*, Papua New } \\
\text { Guinea, Poland, Qatar*, Saudi Arabia*, most countries } \\
\text { of the former Soviet Union, St Kitts and Nevis, Syria, Turks and Caicos } \\
\text { Islands, United Arab Emirates }\end{array}$ & $\begin{array}{l}\text { Students and/or foreign resident workers (for stays } \\
\text { ranging from a few days to } 12 \text { months) }\end{array}$ \\
\hline Australia, Kuwait, Libya, Philippines*, Poland, Pakistan* & $\begin{array}{l}\text { Foreigners applying for permanent residence visas or for pro- } \\
\text { longed stays }\end{array}$ \\
\hline $\begin{array}{l}\text { Antigua and Barbados, Australia, France, Hungary, Singapore, } \\
\text { South Africa, Sri Lanka, Thailand, Turkey, United States }{ }^{\dagger}\end{array}$ & $\begin{array}{l}\text { Visitors suspected of having AIDS may be refused entry or } \\
\text { may be required to be tested for HIV }\end{array}$ \\
\hline
\end{tabular}

${ }^{*}$ Excluding diplomats; ${ }^{\dagger}$ May apply for a waiver in advance if planning to attend a conference, receive medical treatment, visit relatives or do business. HIV Human immunodeficiency virus

types of activities. Hepatitis A vaccine is very safe and effective. It protects against a virus transmitted through contaminated food and water. It is recommended to all HIV travellers planning to travel to developing countries. If you intend to travel for prolonged periods (longer than three months) or to venture off main tourist routes into rural areas, the new inactivated vaccine against typhoid fever (Typhim vi, Connaught Laboratories) is recommended. Japanese encephalitis vaccine is recommended if you are travelling for several weeks in rural areas of Southeast Asia, especially during the monsoon (summer) months. Rabies vaccination is available for those travellers who intend to spend three months or more in an area where rabies is a constant threat. Information regarding rabies endemic areas can be obtained from a travel clinic or public health department. Although tuberculosis is found throughout the developing world there is no highly effective vaccine. Since the only vaccine available, BCG, is a live vaccine, it is not recommended for HIV-infected persons.

\section{TRAVELLERS WITH SPECIAL NEEDS}

AIDS patients and those on HIV medications such as zidovudine (AZT) often suffer from anemia. During air travel, the cabin is only partially pressurized to an equivalent of around $2500 \mathrm{~m}$. This can cause respiratory distress to someone with a hemoglobin level of $85 \mathrm{~g} / \mathrm{L}$ or less. To avoid this problem, it is quite straightforward to make arrangements for oxygen to be available during a flight. Your physician needs to call the airline at least $48 \mathrm{~h}$ in advance with all the information concerning your condition, the date of departure, flight number, connections, etc. A prescription of $2 \mathrm{~L} / \mathrm{min}$ is usually enough and will be sufficient for 6 to $8 \mathrm{~h}$ of flying time. Don't forget to shut off the oxygen during meals and when you leave your seat. For maximum comfort, ask for nasal cannula. Special meals are available from most airlines. Arrangements need to be made by the traveller directly or by his or her travel agent. Drink liberally during your flight but try to avoid caffeine and alcohol. Carbonated beverages will increase abdominal distension and should be avoided if you already have such a problem. You can easily bring herbal teas with you for use during flight.

If you need a wheelchair, don't hesitate to ask for one when you arrive at the terminal. An agent from the airline can assist you with luggage check-in and during all formalities. Travel itself is exhausting. Save your energy for your vacation! Many hotels have special rooms to accommodate wheelchairs.

If you need to use a bladder catheter, remember to fill the 'balloon' with water and not with air before air travel. With depressurization during flight the air will expand and potentially could damage the urine passage.

If you are legally blind, you might be refused on board a ship, even if you are accompanied by a sighted person. Cruises are expensive; be sure to check for any restrictions before you buy your ticket.

\section{RESTRICTIONS FOR CROSSING BORDERS}

Over 50 countries have policies that discriminate against HIV-infected travellers, migrants and students. Many countries restrict only certain classes of travellers. For example, migrant workers and foreign students often need to be screened for HIV, whereas short term tourists are usually exempt. Information on the countries requiring such a test changes rapidly. You should check with consulates or embassies before making arrangements for your trip. Table 2 is a representative list of some countries in which restrictions apply.

The transportation of drugs, such as morphine and other opiates, and of syringes and needles may complicate the traveller's passage through customs. Thus, a letter and prescription from your physician is essential. Keep in mind that immigration officials in some countries will be searching luggage for drugs such as zidovudine or didanosine in order to identify HIV-infected individuals. Changing the labels on your pill containers will rarely help to avoid this problem because customs officials usually recognize the drugs easily. United States customs agents are particularly good at it! Keep in mind that you may have difficulties obtaining your medica- 
tions overseas; take a supply that will last for the duration of your trip. Also, you might wish to send your medication by mail or courier in advance to the first address on your itinerary; this approach usually works quite well.

\section{WHEN YOU RETURN}

Back home, you may experience unusual symptoms. Do not hesitate to consult your physician for advice and possible treatment. Any fever should be evaluated as a medical emergency. Malaria should always be the first diagnosis to be ruled out after a stay in a tropical area even if you took chemoprophylaxis as prescribed. Since fever is a common finding in those infected with HIV, malaria is not usually considered. Mention to your physician that you have recently returned from a malarious area and that you wish to have blood films examined for malaria.

\section{CONCLUSIONS}

Being HIV-positive or having AIDS should not prevent you from enjoying the rewards of travel if you are aware of the risks involved and have taken the necessary precautions to minimize them. The risk of acquiring an infectious disease is increased by travelling off the usual tourist routes in developing countries and by failure to take reasonable precautions concerning food, water and insect bites. The severity of a travel-related illness may be related to your level of immune function (CD4 count) and general health status before depar- ture. The most important question to ask is: "Do the benefits of travel exceed the risks?" After discussion with your health care provider, perhaps with the assistance of a travel medicine expert, you should be able to come to an informed decision. However, it would be an understatement to say that many physicians are paranoid about the hazards of overseas travel because they do not fully appreciate the ways to prevent illness and/or because they have never experienced the pleasure of travel themselves. The final decision to travel should not be made by your health care provider; it should be yours, and yours alone.

\section{ADDITIONAL READING}

1. Wilson ME, von Rein CF, Fineberg HV. Infection in HIV-infected travelers: risks and prevention. Ann Intern Med 1991;114:582-92.

2. Wilson ME. Travelling with HIV. AIDS Clinical Care 1991;3:49-51.

3. Centers for Disease Control and Prevention. Health Information for International Travel 1994. US Department of Health and Human Services Publication No (CDC) 94-8280. Atlanta: US Department of Health and Human Services, 1994.

4. Sanford JP, Sande MA, Gilbert DN, Gerberding JL. The Sanford Guide to HIVIAIDS Therapy. Dallas: Antimicrobial Therapy Inc, 1993.

5. Canadian Immunization Guide, 4th edn. Ottawa: Health Canada, 1993.

6. Tessier D, Fréchette G. VIH et voyages: Conseils relatifs aux immunisations à l'évaluation pré-voyages. Can Fam Physician 1994;40:740-5. 


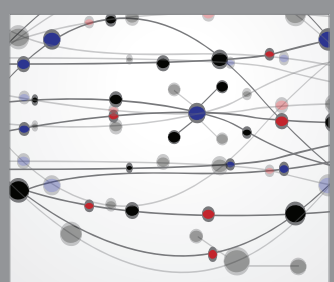

The Scientific World Journal
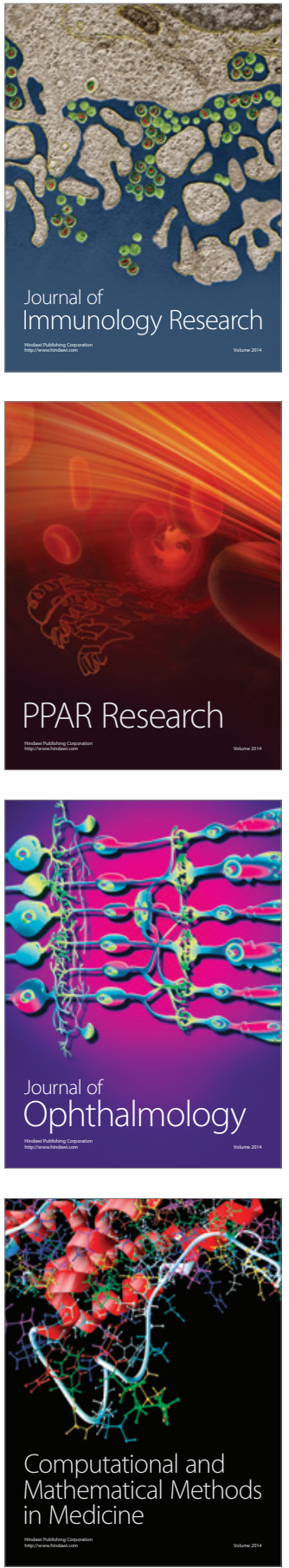

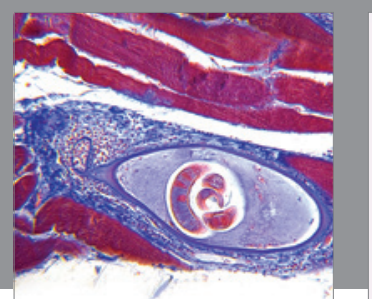

Gastroenterology Research and Practice

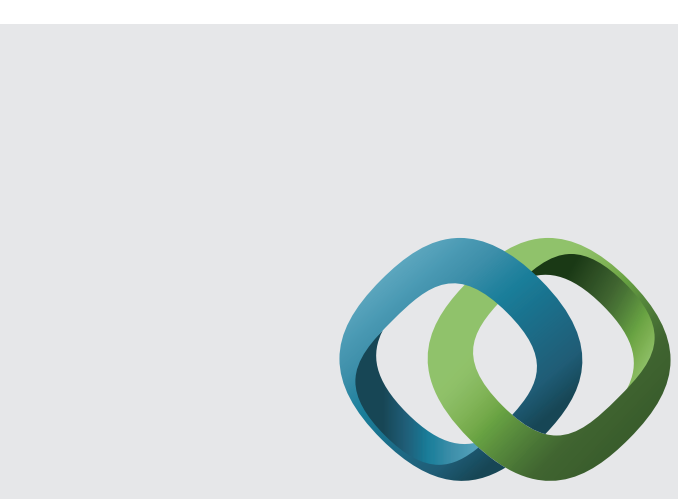

\section{Hindawi}

Submit your manuscripts at

http://www.hindawi.com
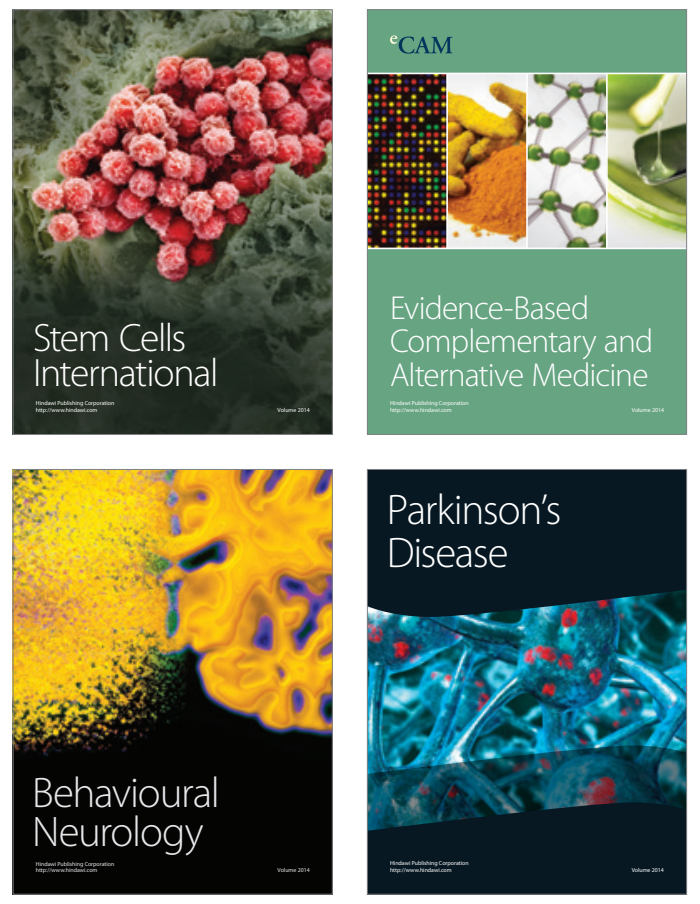
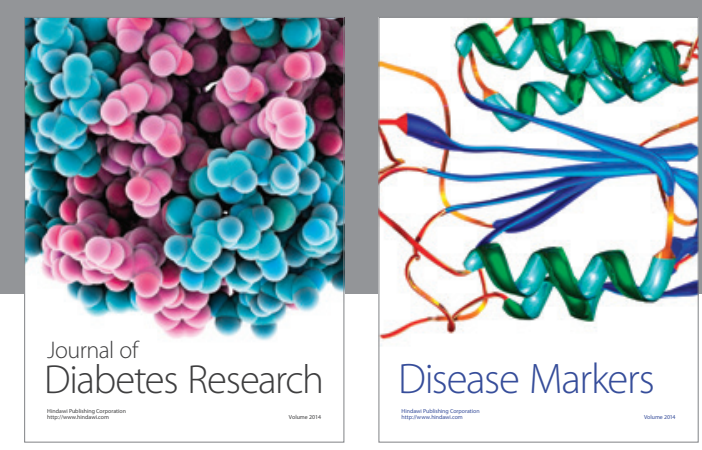

Disease Markers
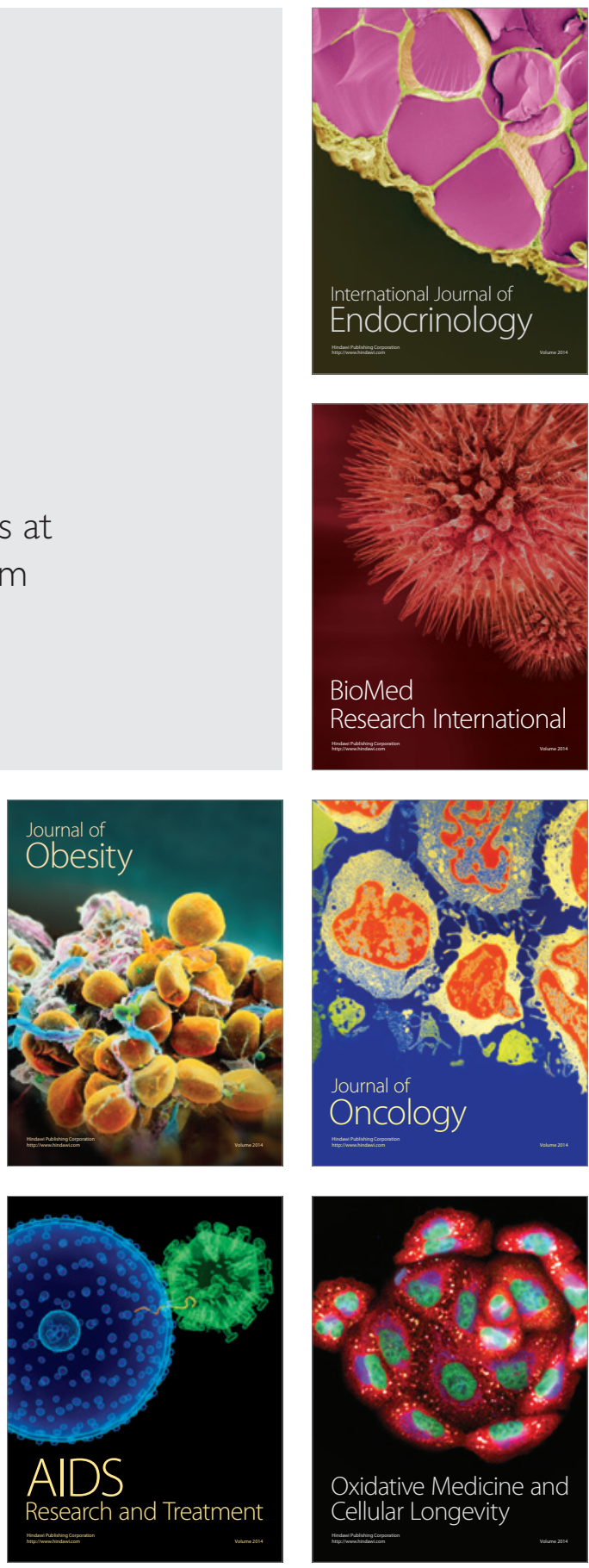